\title{
Anaplastic (Malignant) Meningioma
}

National Cancer Institute

\section{Source}

National Cancer Institute. Anaplastic (Malignant) Meningioma. NCI Thesaurus. Code C4051.

A WHO grade III mening ioma characterized by the presence of malignant morphologic features, including malignant cytology and a very high mitotic index (20 or more mitoses per ten high power fields). 